\title{
Analysis of Postoperative Complications Following Laparoscopic Gastrectomy in 1332 Gastric Cancer Patients
}

\author{
Min Chan Kim, M.D., Ph.D. \\ Department of Surgery, Dong-A University College of Medicine, Busan, Korea
}

Corresponding author

Min Chan Kim

Department of Surgery, Dong-A University College of Medicine, 32 Daesingongwon-ro, Seo-gu, Busan 49201, Korea

Tel: +82-51-240-2643, Fax: +82-51-247-9316, E-mail: mckim@donga.ac.kr

The laparoscopic gastrectomy is still one of challenging fields for treatment of gastric cancer patient. Morbidity of laparoscopic distal gastrectomy for stage I gastric cancer was decreased (13.0 vs. $19.9 \%, p=0.001)$ comparing with open distal gastrectomy from a multicenter randomized controlled trial (KLASS-01). ${ }^{1}$ And also, morbidity results of KLASS-02 for locally advanced gastric cancer was similar with those of KLASS-01 (unpublished). Long-term survival results of laparoscopic distal gastrectomy for stage I gastric cancers were not inferior with those of open distal gastrectomy from KLASS-01 (unpublished). However, there is no prospective result of long-term survival for advanced gastric cancer treated by laparoscope in Korea and China.

So far, there are many studies of short-term results and risk factor with related morbidity of laparoscopic gastrectomy for gastric cancer. ${ }^{2-5}$ This article is a single center, retrospective and multi-investigators study about postoperative complication following laparoscopic gastrectomy using prospectively designed data collecting system for 8 years. This study included three methods of operation and several methods of reconstruction. However, most patients were performed laparoscopy-assisted distal gastrectomy with B-I reconstruction. Overall (16.7\%) and major (2.9\%) complication rates of this study were comparable to those of other studies. I think that this article has two advantages in terms of morbidity study; 1) high rate of $\mathrm{C}-\mathrm{D}$ grade I or II, and 2) low mortality rate $(0.1 \%)$. The high rate of $\mathrm{C}-\mathrm{D}$ grade I or II can reflect the reliability of their prospectively designed data collecting system. Moreover, authors had an excellent multidepartment team for treatment of postoperative complication. Their severe complications related to anastomosis were successfully managed.

In this study, several risk factors related with overall postoperative complication such as sex, co-morbidity, D2 lymph node dissection, operative method, co-resection, operation time and blood loss are understandable and acceptable. I agree author's conclusion that the beginner can safely perform laparoscopic gastrectomy for stage I gastric cancer through the strict patient selection, even though their study is slightly out of date.

\section{REFERENCES}

1) Kim W, Kim HH, Han SU, et al. Decreased Morbidity of Laparoscopic Distal Gastrectomy Compared With Open Distal Gastrectomy for Stage I Gastric Cancer: Short-term Outcomes From a Multicenter Randomized Controlled Trial (KLASS-01). Ann Surg 2016;263:28-35.

2) Oh SY, Kwon S, Lee KG, et al. Outcomes of minimally invasive surgery for early gastric cancer are comparable with those for 
open surgery: analysis of 1,013 minimally invasive surgeries at a single institution. Surg Endosc 2014;28:789-795.

3) Kim MC, Kim W, Kim HH, et al. Risk factors associated with complication following laparoscopy-assisted gastrectomy for gastric cancer: a large-scale korean multicenter study. Ann Surg Oncol 2008;15:2692-2700.

4) Kim MC, Kim KH, Kim HH, Jung GJ. Comparison of laparosco- py-assisted by conventional open distal gastrectomy and extraperigastric lymph node dissection in early gastric cancer. J Surg Oncol 2005;91:90-94.

5) Katai H, Sasako M, Fukuda H, et al. Safety and feasibility of laparoscopy-assisted distal gastrectomy with suprapancreatic nodal dissection for clinical stage I gastric cancer: a multicenter phase II trial (JCOG 0703). Gastric Cancer 2010;13:238-244. 